\title{
Risk of Egg Parasitoid Attraction Depends on Anti-aphrodisiac Titre in the Large Cabbage White Butterfly Pieris brassicae
}

\author{
Martinus E. Huigens • Erik de Swart • Roland Mumm
}

Received: 28 December 2010 /Revised: 22 February 2011 / Accepted: 11 March 2011 /Published online: 31 March 2011

(C) The Author(s) 2011. This article is published with open access at Springerlink.com

\begin{abstract}
Males of a variety of insects transfer an antiaphrodisiac pheromone to females during mating that renders them less attractive to conspecific males. In cabbage white butterflies, the transfer of an anti-aphrodisiac can result in the unwanted attraction of tiny egg parasitoid wasps of the genus Trichogramma that hitch-hike with mated female butterflies to a host plant where they parasitize the freshly laid butterfly eggs. Here, we show that the anti-aphrodisiac benzyl cyanide (BC) of the large cabbage white Pieris brassicae is depleted by frequent display of the mate-refusal posture that signals a female's unreceptivity to mating. This depletion of BC is ecologically important because it results in a reduced risk of attracting the hitch-hiking egg parasitoid Trichogramma brassicae to mated female butterflies over time since mating. Our results indicate for the first time that a reduction in antiaphrodisiac titre in mated females due to frequent adoption of the mate-refusal posture is beneficial to both mated females and males particularly when parasitoid pressure is high.
\end{abstract}

Key Words Benzyl cyanide · Pheromone · Polygamy · Mate-refusal posture $\cdot$ Chemical espionage $\cdot$ Trichogramma brassicae

\author{
M. E. Huigens $(\varangle) \cdot$ E. de Swart $\cdot$ R. Mumm \\ Laboratory of Entomology, Department of Plant Sciences, \\ Wageningen University, \\ P.O. Box 8031, 6700 EH Wageningen, The Netherlands \\ e-mail: ties.huigens@wur.nl \\ R. Mumm \\ Plant Research International, \\ Wageningen University and Research Centre, \\ P.O. Box 16, 6700 AA Wageningen, The Netherlands \\ R. Mumm \\ Centre for BioSystems Genomics, \\ P.O. Box 98, 6700 AB Wageningen, The Netherlands
}

\section{Introduction}

In various butterfly species with female polygamy, the male transfers an anti-aphrodisiac pheromone blend to the female during mating to reinforce monogamy (Andersson et al., 2000, 2003, 2004; Schulz et al., 2008). This not only benefits the male, because it reduces the risk of sperm competition, but also the recently mated female, because a reduced harassment by other males enables her to invest more in offspring production (Forsberg and Wiklund, 1989). However, the use of an anti-aphrodisiac is vulnerable to chemical espionage by natural enemies (Fatouros et al., 2005b; Huigens et al., 2009, 2010).

Males of the large cabbage white butterfly Pieris brassicae transfer the anti-aphrodisiac benzyl cyanide (BC) to females during mating, which renders them less attractive to conspecific males, whereas males of the greenveined white Pieris napi transfer methyl salicylate (MeSA) (Andersson et al., 2000, 2003, 2004). In P. napi, the storage of MeSA in the mated female is depleted over time after mating by frequent adoption of a posture that signals unreceptivity to mating (Andersson et al., 2004). This so called 'mate-refusal' posture with spread wings and elevated abdomen is displayed both at male and female butterflies and is typical for all Pieridae (Obara, 1964).

In this study, we examined whether depletion of an antiaphrodisiac has ecological consequences for both male and female butterflies. Recently, we discovered how the use of the anti-aphrodisiac BC in P. brassicae can be exploited by the tiny egg parasitoid wasps Trichogramma brassicae and T. evanescens; after the wasps detect $\mathrm{BC}$ released by a female butterfly on day 1 after mating, they mount her and hitch a ride to a host plant where they parasitize her freshly laid eggs (Fatouros et al., 2005b; Huigens et al., 2009). Here, we investigated whether the amount of $\mathrm{BC}$ released by mated 
female $P$. brassicae butterflies a) changes over time since mating, b) is influenced by frequent display of the materefusal posture, and c) mediates the risk of attracting the hitchhiking egg parasitoid T. brassicae to mated female butterflies.

\section{Methods and Materials}

Butterflies and Wasps Pieris brassicae L. (Lepidoptera: Pieridae) butterflies and Trichogramma brassicae Bezdenko (Hymenoptera: Trichogrammatidae) wasps (iso-female strain Y175) were reared as described in previous studies (Fatouros et al., 2005a, b; Huigens et al., 2009). We used only mated, 2-dold female wasps in the experiments. Singly-mated female butterflies were obtained by adding virgin males to virgin females in a cage $(50 \times 50 \times 50 \mathrm{~cm}) 2$ days after eclosion. Mating couples were individually isolated in plastic cylinders (15 cm i.d., $30 \mathrm{~cm}$ high) covered with a gauze lid. After a couple had separated, the male was removed, and the female was provided daily with fresh honey water $(10 \%)$. On day 1 after mating, females were kept individually, and volatiles were collected for $1.5 \mathrm{hr}$ (see below). After BC collection, females were either housed individually, or housed together with 6 other mated females. Benzyl cyanide was collected again on day 5 after mating (Andersson et al., 2004). All butterflies were active, but females only (frequently) displayed the mate-refusal posture when housed in a group (Andersson et al., 2004).

Emission of $B C$ A dynamic headspace system was used to collect BC that is released by one singly-mated female butterfly. An individual female was confined in a glass jar (0.5 L, Weck, Germany) that was closed with a Viton-lined glass lid having an inlet and outlet. Inlet air was filtered by passing through a stainless steel cartridge filled with $200 \mathrm{mg}$ of charcoal. Volatiles were trapped by sucking air out of the jar at a rate of $100 \mathrm{ml} \mathrm{min}^{-1}$ through a similar cartridge filled with 200 mg Tenax TA (20/35 mesh; Grace-Alltech, USA). Benzyl cyanide was collected for $1.5 \mathrm{hr}$ on day 1 and day 5 after mating. To determine whether a female butterfly releases more $\mathrm{BC}$ when it displays the mate-refusal posture, we added a virgin [BC free (Andersson et al., 2003)] female butterfly to the glass jar during volatile trapping. Headspace samples were analyzed with a Thermo Trace GC connected to a DSQ mass spectrometer (Thermo Fisher Scientific, USA). Volatiles were thermally desorbed from Tenax cartridges at $250^{\circ} \mathrm{C}$ for 3 min (Ultra, Markes Llantrisant, UK) with a helium flow of $30 \mathrm{ml} \mathrm{min}$. Analytes were focused at $0^{\circ} \mathrm{C}$ on an electronically-cooled sorbent trap (Unity, Markes, Llantrisant, UK) and were then transferred in splitless mode to the analytical column (ZB-5Msi, $30 \mathrm{~m}, 0.25 \mathrm{~mm}$ i.d., $1.0 \mu \mathrm{m}$ film thickness, Phenomenex, USA) by rapid heating of the cold trap to $250^{\circ} \mathrm{C}$ for $5 \mathrm{~min}$. The temperature gradient of the GC was as follows: $60^{\circ} \mathrm{C}$ hold for $3 \mathrm{~min}, 10^{\circ} \mathrm{C} \mathrm{min} \mathrm{min}^{-1}$ gradient to $200^{\circ} \mathrm{C}$, then $40^{\circ} \mathrm{C} \mathrm{min}^{-1}$ gradient to $280^{\circ} \mathrm{C}, 2 \mathrm{~min}$ hold, constant column flow of $1 \mathrm{ml} \mathrm{min}^{-1}$ ). Mass spectra were acquired by electron impact ionization $(70 \mathrm{eV})$ with a scanning from $45-200 \mathrm{~m} / \mathrm{z}$ with a scan rate of 7.3 scans $\mathrm{s}^{-1}$. Benzyl cyanide was identified by comparing the mass spectrum and retention time with an authentic reference standard. A linear calibration curve made from 0.1, 1, 10, 100 , and $1000 \mathrm{ng}$ synthetic BC was used to determine the amount of $\mathrm{BC}$ released by mated female butterflies.

Wasp Response to Mated Female Butterfly Odors In a static two-chamber olfactometer, we tested the response of T. brassicae to odors released by differently treated singly-mated female butterflies $(1 \mathrm{dI}=1$ day after mating, housed individually; $5 \mathrm{dI}=5$ days after mating, housed individually; $5 \mathrm{dG}=5$ days after mating, housed in a group) as previously described (Fatouros et al., 2005b; Huigens et al., 2009, 2010). The olfactometer differed only in height $(7 \mathrm{~cm})$ from the one that was used before $(18 \mathrm{~cm})$. One $P$. brassicae female per chamber was introduced as odor source. The time spent (residence time) by the wasps in one of the two odor fields was observed for $300 \mathrm{sec}$.

\section{Results and Discussion}

The gas chromatography-mass spectrometry (GC-MS) analysis shows that the storage of $\mathrm{BC}$ in mated female $P$. brassicae butterflies is depleted over time by frequent display of the mate-refusal posture. Co-habitating female butterflies released significantly less BC on day 5 than on day 1 (Fig. 1a; Wilcoxon signed-rank test, $P=0.003$ ). This is consistent with the fact that when housed in a group, females frequently adopted the male-refusal posture (Andersson et al., 2004). This posturing does not occur as frequently when a female is housed individually (Andersson et al., 2004). Therefore, BC levels emitted from individually housed females were lower than day 1 levels, although they were not statistically different (Fig. 1a; Wilcoxon signed-rank test, $P=0.480$ ). On day 5 after mating, female butterflies that were housed alone also released significantly more $\mathrm{BC}$ than those that were housed in a group (Fig. 1a; Mann-Whitney $U$ test, $P=0.002$ ). Moreover, mated female butterflies that were maintained together with a virgin female during volatile trapping, and consequently exhibited the mate-refusal posture, released significantly more $\mathrm{BC}$ than those that were maintained alone (Fig. 1a; Mann-Whitney $U$ test, $P=0.001$ ). The antiaphrodisiac thus, is released mostly during the mate-refusal posture in $P$. brassicae, just as in P. napi (Andersson et al., 2004), thereby suggesting this phenomenon to be more widespread among Pierid butterflies. 
A

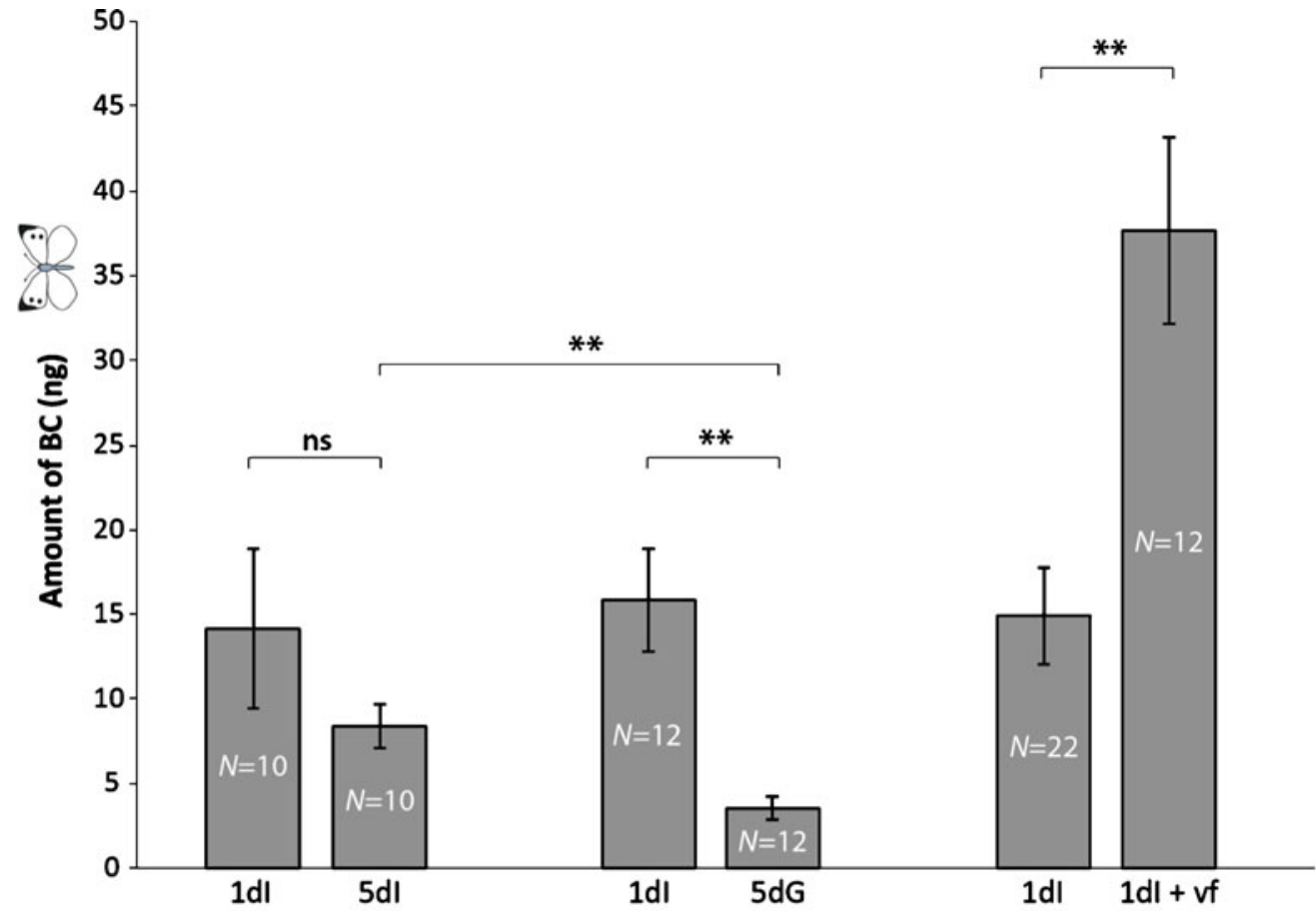

B
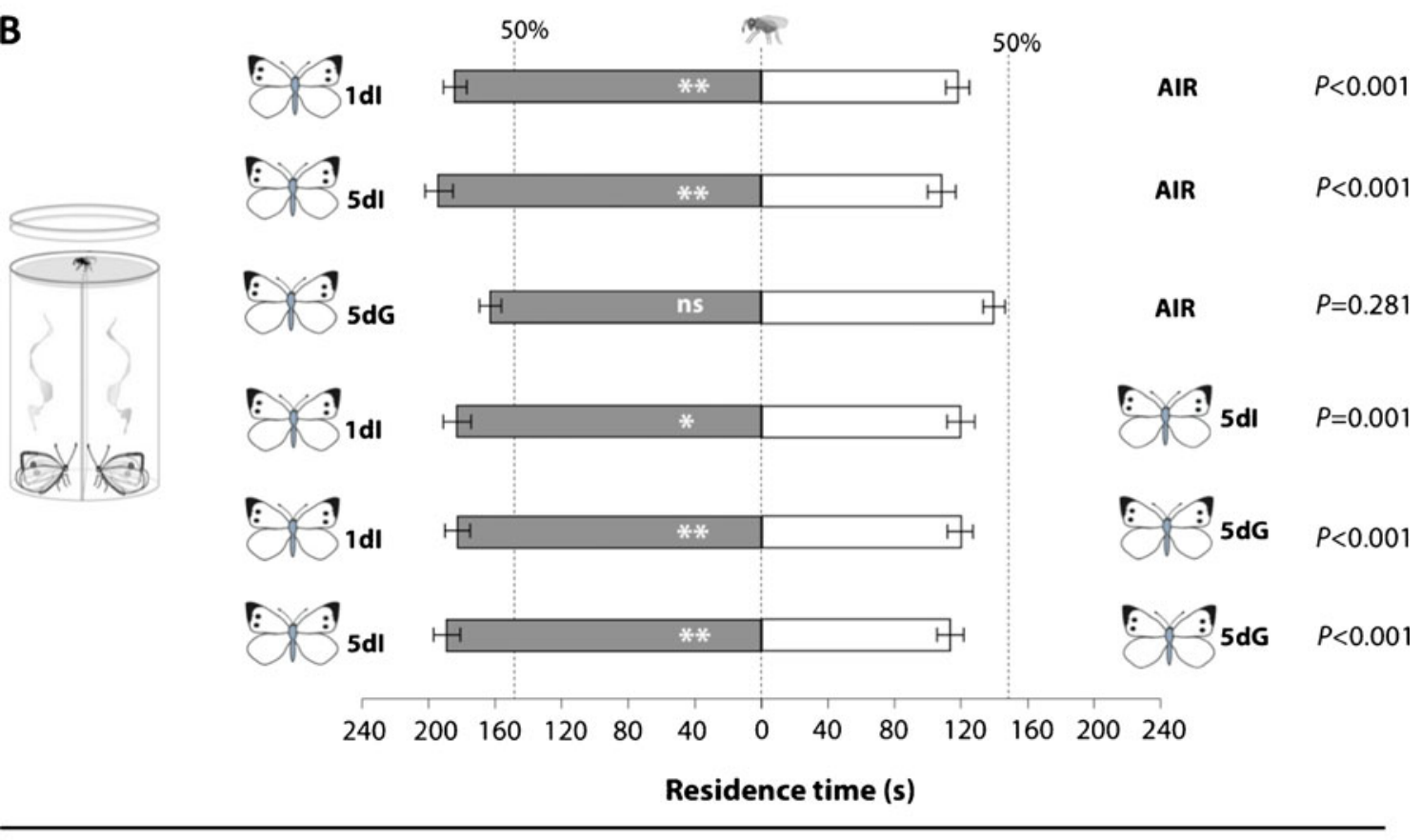

= Female $T$. brassicae

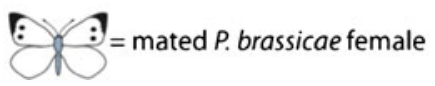

Fig. 1 a Amount of BC (ng) released by differently treated singlymated females of the large cabbage white butterfly Pieris brassicae on day 1 and days 5 after mating during $1.5 \mathrm{hr}$ of volatile trapping. b Response of Trichogramma brassicae wasps to the odors of differently treated singly-mated female butterflies on day 1 and days 5 after mating; mean residence time ( \pm s.e.m.) in two odor fields in a static olfactometer; $N=40$ wasps tested per experiment. $1 \mathrm{dI}=1$ day after mating, housed individually; $5 \mathrm{dI}=5$ days after mating, housed individually; $5 \mathrm{dG}=5$ days after mating, housed in group; $1 \mathrm{dI}+\mathrm{vf}=1$ day after mating, housed individually, accompanied by a virgin (BC free) $P$. brassicae female during volatile trapping. In a, a Wilcoxon signed-rank test was used for comparisons of $1 \mathrm{dI}$ with $5 \mathrm{dI}$ (same female butterflies) and $1 \mathrm{dI}$ with $5 \mathrm{dG}$ (same female butterflies), and a Mann-Whitney U test for comparisons of $5 \mathrm{dI}$ with $5 \mathrm{dG}$ (different female butterflies) and $1 \mathrm{dI}$ with $1 \mathrm{dI}+\mathrm{vf}$ (different female butterflies). In $\mathbf{b}$, we used a Wilcoxon signed-rank test for comparisons within a choice test. Asterisks indicate significant differences, ${ }^{* *} P<0.01$, ns: not significant 
Our results indicate that a depletion of $\mathrm{BC}$ in female $P$. brassicae butterflies over time since mating has important ecological consequences. In two-choice olfactory bioassays, T. brassicae wasps showed clear odor preferences for mated P. brassicae females that released the largest amount of $\mathrm{BC}$. When offered against clean air, odors of female butterflies that were housed alone significantly arrested the wasps on day 1 and day 5 after mating (Fig. 1b; Wilcoxon signed-rank test, $P<0.001$ and $P<0.001$, respectively). However, wasps did not discriminate between odors of female butterflies that were housed in a group until day 5 after mating and clean air (Fig. 1b; Wilcoxon signed-rank test, $P=0.281$ ). Wasps also were more strongly arrested by female butterfly odors 1 day after mating when tested against odors of female butterflies that were either housed alone, or in a group, until day 5 after mating (Fig. 1b; Wilcoxon signed-rank test, $P<0.001$ and $P<$ 0.001 , respectively). Although the amount of $\mathrm{BC}$ released by 5-d-individually housed mated females is not significantly lower than that released by 1-d-individually housed mated females, it might be sufficiently lower to result in a reduced arrestment of $T$. brassicae wasps.

In nature, recently mated female $P$. brassicae butterflies are likely to run a higher risk of attracting the hitch-hiking egg parasitoid T. brassicae than do older mated females that have frequently adopted the mate-refusal posture, and consequently emit less BC. The mutual benefit of using an anti-aphrodisiac for both the mated female and the male (Forsberg and Wiklund, 1989; Andersson et al., 2004) could turn into a conflict over time after mating, because the female may benefit later from mating a second time, i.e., from a reduction in anti-aphrodisiac release, whereas the male does not (Andersson et al., 2004). Our results, however, suggest that a decrease in anti-aphrodisiac emission by the female due to a frequent display of the mate-refusal posture after mating also is beneficial for the male because it reduces the risk of indirectly attracting natural enemies to his offspring via the mated female.

Acknowledgements The authors thank Nina Fatouros for discussion and comments on the manuscript, Danielle Lucas-Barbosa for assistance with rearing parasitoid wasps, and Léon Westerd, Frans van Aggelen, and André Gidding for butterfly rearing. Two anonymous reviewers are acknowledged for valuable comments on the manuscript. We thank the Netherlands Organization for Scientific Research (NWO/ALW VENI grant 863.05.020 to M.E.H.) for funding. R.M. was partly financed by the EU 6th FP project METAPHOR (2006-FOOD-CT-036220) together with the Centre for BioSystems Genomics, an initiative under the auspices of the Netherlands Genomics Initiative (NGI).

Open Access This article is distributed under the terms of the Creative Commons Attribution Noncommercial License which permits any noncommercial use, distribution, and reproduction in any medium, provided the original author(s) and source are credited.

\section{References}

Andersson, J., Borg-Karlson, A.-K., and Wiklund, C. 2000. Sexual cooperation and conflict in butterflies: a male-transferred anti-aphrodisiac reduces harassment of recently mated females. Proc. R. Soc. Lond. B 267:1271-1275.

Andersson, J., Borg-Karlson, A.-K., and Wiklund, C. 2003 Antiaphrodisiacs in pierid butterflies: a theme with variation! $J$. Chem. Ecol. 29:1489-1499.

Andersson, J., Borg-Karlson, A.-K., and Wiklund, C. 2004. Sexual conflict and anti-aphrodisiac titre in a polyandrous butterfly: male ejaculate tailoring and absence of female control. Proc. R. Soc. Lond. B 271:1765-1770.

Fatouros, N. E., Bukovinszkine'Kiss, G., Kalkers, L. A., Soler GamborenA, R., Dicke, M., and Hilker, M. $2005 \mathrm{a}$. Oviposition-induced plant cues: do they arrest Trichogramma wasps during host location? Entomol. Exp. Appl. 115:207-215.

Fatouros, N. E., Huigens, M. E., van Loon, J. J. A., Dicke, M., and HiLkeR, M. 2005b. Chemical communication: butterfly antiaphrodisiac lures parasitic wasps. Nature 433:704.

ForsBERG, J. and WIKLUND, C. 1989. Mating in the afternoon: timesaving in courtship and remating by females of a polyandrous butterfly Pieris napi. Behav. Ecol. Sociobiol. 25:349-356.

Huigens, M. E., Pashalidou, F. G., Qian, M.-H., Bukovinszky, T., SMID, H. M., van LoON, J. J. A., Dicke, M., and FATOUROS, N. E. 2009. Hitch-hiking parasitic wasp learns to exploit butterfly anti-aphrodisiac. Proc. Nat. Acad. Sci. U.S.A. 106:820-825.

Huigens, M. E., Woelke, J. B., Pashalidou, F. G., Bukovinszky, T., SMID, H. M., and Fatouros, N. E. 2010. Chemical espionage on species-specific butterfly anti-aphrodisiacs by hitchhiking Trichogramma wasps. Behav. Ecol. 21:470-478.

OBARA, Y. 1964. Mating behavior of the cabbage white, Pieris rapae crucivora II: the mate-refusal' posture of the female. Zool. Mag. 73:175-178.

Schulz, S., Estrada, C., Yildizhan, S., Boppre, M., and Gilbert, L. E. 2008. An antiaphrodisiac in Heliconius melpomene butterflies. J. Chem. Ecol. 34:82-93. 